\title{
Inflammatory Gene Expression Upon TGF- $\beta 1$-Induced p38 Activation in Primary Dupuytren's Disease Fibroblasts
}

\begin{abstract}
Maro Bujak ${ }^{1}$, Ivana Ratkaj ${ }^{2}$, Elitza Markova-Car ${ }^{2}$, Davor Jurišić ${ }^{3}$, Anita Horvatić ${ }^{\text {, }}$ Srđan Vučinić ${ }^{1}$, Jonatan Lerga ${ }^{4,5}$, Mirela Baus-Lončar ${ }^{1}$, Krešimir Pavelić ${ }^{2}$ and Sandra Kraljević Pavelić ${ }^{2 *}$

${ }^{1}$ Division of Molecular Medicine, Ruđer Bošković Institute, Zagreb, Croatia, ${ }^{2}$ Department of Biotechnology, Centre for High-Throughput Technologies, University of Rijeka, Rijeka, Croatia, ${ }^{3}$ Clinic for Surgery, Department for Plastic and Reconstructive Surgery, University Hospital Centre Rijeka, Rijeka, Croatia, ${ }^{4}$ Faculty of Engineering and Centre for Advanced Computing and Modelling, University of Rijeka, Rijeka, Croatia, ${ }^{5}$ Centre for Advanced Computing and Modelling, University of Rijeka, Rijeka, Croatia
\end{abstract}

Objectives: Inflammation is an underlying mechanism behind fibrotic processes and differentiation of cells into myofibroblasts. Presented study therefore provides new data on activation of autoimmune and inflammatory immune response genes that accompany activation of p38 and cell differentiation in primary cells derived from Dupuytren's disease (DD) patients.

Edited by: Ashok Sharma, Georgia Regents University, USA

Methods: Primary non-Dupuytren's disease cells (ND) were isolated from macroscopically unaffected palmar fascia adjacent to diseased tissue obtained from patients diagnosed with the last stage of DD and cultured in vitro. Gene expression, collagen gel contraction assay and analysis of secreted proteins were performed in ND cells treated with TGF- $\beta 1$ and/or inhibitor of p38 phosphorylation.

Results: During differentiation of ND fibroblasts, increased expression of immune response genes PAI-1, TIMP-1, CCL11, and IL-6 was found. These changes were accompanied by increased cell contractility and activation of p38 and its target kinase MK2. Inhibition of p38 phosphorylation reversed these processes in vitro.

Conclusions: TGF- $\beta 1$ induced p38 phosphorylation in ND cells grown from macroscopically unaffected palmar fascia adjacent to diseased tissue from DD patients. This was accompanied by activation of the cytokine genes CCL-11 and IL-6 and secretion of extracellular matrix regulatory proteins PAI-1 and TIMP-1. A combined approach directed toward inflammation and p38 MAPK-mediated processes in DD might be considered for improving management of DD patients and prevention of recurrence.

Keywords: inflammatory genes, myofibroblasts, p38 MAPK, MK2 kinase, extracellular-matrix

\section{INTRODUCTION}

Fibrotic and fibroproliferative disorders may affect all tissues causing loss of tissue structure and function (Wynn, 2008). This process involves differentiation of cells into myofibroblasts accompanied by extracellular matrix deposition. Benign and malignant fibroproliferative disorders 
include idiopathic pulmonary fibrosis, hepatic cirrhosis, myelofibrosis, systemic sclerosis, Dupuytren's disease (DD), hypertrophic scars, and keloids (Huang and Ogawa, 2012). Common mechanisms occur in these fibrotic processes that include persistent inflammation and local overproduction/activation of different cytokines (Ghosh and Vaughan, 2012; Huang and Ogawa, 2012). For example, infiltrating immune cells in DD excrete large amount of different cytokines, chemokines and growth factors, especially TGF- $\beta 1$ (Baird et al., 1993), cytokine that induces typical phenotypic changes and inflammation (Parsonage et al., 2005; Lupher and Gallatin, 2006). Under such conditions, cells may acquire myofibroblast phenotype. Myofibroblasts are active components of innate immune system and may regulate switches from acute to chronic inflammation (Kalluri and Zeisberg, 2006). In particular, activated myofibroblasts express MHC I and MHC II antigens (Brennan et al., 1990; Knittel et al., 1999) and respond to pro-inflammatory cytokines TNF- $\alpha$ and IFN- $\gamma$ by releasing chemokine CCL2 (Marra et al., 1993), inflammatory mediators IL-1, IL-6, IL-8, prostaglandins and hyaluronate (Yellin et al., 1995; Sempowski et al., 1997; Schwabe et al., 2001). Moreover, during wound healing, phagocyte apoptotic cells and activate TGF- $\beta 1$, a central mediator of fibrosis (Canbay et al., 2003). Molecular mechanisms underlying fibroproliferative disorders have been studied for years by different approaches including modern large-scale methodologies but effective treatments for this group of disease are still missing. For example, surgery is still the only available option for DD patients even though high recurrence rates are usually observed. Novel potential therapeutic targets for DD and fibroses have therefore, been studied, including reactive oxygen species-dependant TGF- $\beta$ signaling (Samarakoon et al., 2013), focal adhesion kinases (Lagares and Kapoor, 2013), and inflammatory cytokine TNF (Verjee et al., 2013). In the present paper, we analyzed the expression of pro-inflammatory cytokine genes in primary cells grown from DD patients and found that TGF- $\beta 1$ induced p38 phosphorylation in ND cells grown from macroscopically unaffected palmar fascia adjacent to diseased tissue from DD patients is accompanied by activation of the cytokine genes CCL-11 and IL- 6 and secretion of extracellular matrix regulatory proteins PAI-1 and TIMP-1, which casts new light on pathogenesis of DD.

\section{MATERIALS AND METHODS}

\section{Primary Cell Cultures}

Clinical specimens were collected in strict compliance with the clinic's chief pathologist and the ethics committee for research involving human subject at Clinical Hospital "University Hospital Centre Rijeka” in Croatia. Informed consent was signed by all patients. The cells were isolated according to established protocols (Tse et al., 2004; Pavelic et al., 2009). Primary ND cells were obtained from macroscopically unaffected palmar fascia adjacent to the disease tissue. Tissue samples were collected from six patients (age range 54-75 years, males) diagnosed with the last stage of DD. Second passages were used for all experiments to assure uniformity and prevent loss of original cell phenotype. ND cells were cultured as monolayers and maintained in Dulbecco's modified Eagle medium (DMEM, Gibco, Invitrogen, USA) supplemented with $10 \%$ fetal bovine serum (FBS, Gibco, Invitrogen, USA), 2 mM L-glutamine (Gibco, Invitrogen, USA), $100 \mathrm{U} / \mathrm{mL}$ penicillin (Gibco, Invitrogen, USA), and $100 \mu \mathrm{g} / \mathrm{mL}$ streptomycin (Gibco, Invitrogen, USA) in a humidified atmosphere with $5 \% \mathrm{CO} 2$ at $37^{\circ} \mathrm{C}$ until they reached $80 \%$ confluence.

\section{Western Blotting}

ND cells were treated with TGF- $\beta 1$ or SB203580 inhibitor and TGF- $\beta 1$ for $16 \mathrm{~h}$. Cells were lysed in the buffer containing $50 \mathrm{mM}$ Tris $\mathrm{HCl}$ ( $\mathrm{pH}$ 8), $150 \mathrm{mM} \mathrm{NaCl}, 1 \% \mathrm{NP}-40,0.5 \%$ sodium deoxycolate, $0.1 \%$ SDS, protease inhibitor cocktail (Roche, Basel, Switzerland) and phosphatase inhibitor cocktail (Thermo Scientific, Waltham, Massachusetts, USA). Protein concentration was determined with DC Protein Assay Kit (BIO-RAD, USA) and a total of $40 \mu \mathrm{g}$ of proteins were resolved on $9 \%$ polyacrylamide gels using the Mini-protean cell (Bio-Rad, Foster City, CA, USA), and analysis was performed by previously established procedure (Pavelic et al., 2009). The membranes were incubated with primary antibodies raised against phosphorylated MAPKAPK-2 (MK2; 1:1000, phospho-MAPKAPK-2, Cell Signaling technology, Danvers, Massachusetts, USA) at $4^{\circ} \mathrm{C}$ overnight. Secondary antibody linked to anti-rabbit (1:1300, Dako, Denmark) horseradish peroxidase was used. The signal was visualized by Western Lightening Chemiluminescence Reagent Plus Kit (Perkin Elmer, Waltham, Massachusetts, USA) on the VersaDoc Imaging System 4000 (Bio-Rad, Foster City, CA, USA). $\alpha$-tubulin was used as a loading control (1:1000, Sigma-Aldrich, St. Louis, Missouri, USA).

\section{Expression Analysis of Cytokines and Cytokine Receptors by PCR Array}

For detection of gene expression involved in cytokine inflammatory and autoimmune response pathway-focused $\mathrm{RT}^{2}$ Profiler PCR Array: Human Inflammatory Response and Autoimmunity (PAHS-077A, SABiosciences, Valencia, CA, USA) was used. Analysis was conducted according to manufacturer recommendations. confluent ND cells $(80 \%)$ were deprived of serum for $2 \mathrm{~h}$ prior to treatment with TGF- $\beta 1(3 \mathrm{ng} / \mathrm{mL}$ in serum free medium, R\&D Systems, McKinley Place, MN, USA) and TGF- $\beta 1$ together with the inhibitor of p38 phosphorylation SB203580 (10 $\mu \mathrm{M}$, Calbiochem, Darmstadt, Germany). In dual treatment, cells were first incubated with inhibitor SB203580 for $30 \mathrm{~min}$ and then stimulated with TGF- $\beta 1$. After $16 \mathrm{~h}$ total RNA was isolated using RNAeasy spin columns (Qiagen, Valencia, CA, USA). First strand cDNA synthesis reaction mix containing RT cocktail was incubated with genomic DNA elimination mixture at $42^{\circ} \mathrm{C}$ for $15 \mathrm{~min}$ and afterwards immediately heated at $95^{\circ} \mathrm{C}$ for $5 \mathrm{~min}$. To each of cDNA synthesis reactions, the RNase-free water was added up to $102 \mu \mathrm{l}$ and the samples were stored overnight at $-20^{\circ} \mathrm{C}$. A total of $25 \mu \mathrm{l}$ of prepared experimental cocktail was added to each well of PCR array. Thermal cycling conditions consisted of initial denaturation step, 1 cycle of 
$95^{\circ} \mathrm{C}$ for $10 \mathrm{~min}, 40$ cycles of $95^{\circ} \mathrm{C}$ for $15 \mathrm{~s}$ and annealing and extension at $60^{\circ} \mathrm{C}$ for $1 \mathrm{~min}$. For data analysis, free PCR array data analysis web portal was used (http://www.SABiosciences. com/pcrarraydataanalysis.php).

\section{Protein Fractionation by Sodium Dodecyl Sulfate Polyacrylamide Gel Electrophoresis (SDS-PAGE)}

After $16 \mathrm{~h}$, conditioned media $(20 \mathrm{ml})$ where ND cells treated in the same manner as cell used for expression analysis were grown, was collected on ice, centrifuged at $4^{\circ} \mathrm{C}$ by $1500 \mathrm{rpm}$ for $15 \mathrm{~min}$ to remove cells and debris and supplemented with complete protease inhibitor cocktail (Roche, Basel, Schwitzerland). The samples were concentrated by ultra-filtration (Millipore, Billerica, MA, USA, Centricon, $3 \mathrm{kDa}$ cut-off) at $4^{\circ} \mathrm{C}$ by $12,000 \mathrm{rpm}$. Concentrated samples were dissolved in a buffer containing $7 \mathrm{M}$ urea, $2 \mathrm{M}$ thiourea, $4 \%$ CHAPS, $0.2 \%$ Bio-Lyte ampholyte $\mathrm{pH}$ 3-10 (Bio-Rad), 1\% DTT and 1X protease inhibitor cocktail (Roche, Basel, Schwitzerland). The protein concentration was determined by Bradford Assay (Bio-Rad, Foster City, CA, USA) as described previously (Pavelic et al., 2009).

\section{One-Dimensional Polyacrylamide Gel Electrophoresis}

One-dimensional polyacrylamide gel electrophoresis (SDSPAGE) was performed on a Bio-Rad mini-Protean system. A total of $40 \mu \mathrm{g}$ of proteins were resolved on the $12 \%$ one-dimensional polyacrylamide gel. Gels were stained with Coomassie Brilliant Blue G-250 (Bio-Rad, Foster City, CA, USA) and scanned by VersaDoc Imaging System 4000 (Bio-Rad, Foster City, CA, USA). Qualitative image analysis was carried out using PDQuest SW, 7.0 (Bio-Rad, Foster City, CA, USA).

\section{Trypsin Digestion and Mass Spectrometry}

The lanes were manually excised into 24 bands (eight bands per lane) which were processed for tryptic digestion according to standard protocol (Shevchenko et al., 2006). Briefly, after destaining step with $40 \%$ methanol/10\% acetic acid, gel plugs were incubated with $50 \mathrm{mM}$ ammonium bicarbonate for $10 \mathrm{~min}$ at $37^{\circ} \mathrm{C}$ and then subsequently incubated with $50 \%$ ammonium bicarbonate $/ 50 \%$ acetonitrile $(\mathrm{ACN})$ at $37^{\circ} \mathrm{C}$. After incubation with $50 \%$ acetonitrile for $5 \mathrm{~min}$ at $37^{\circ} \mathrm{C}$ the proteins were digested with $10 \mathrm{ng} / \mu \mathrm{l}$ of trypsin in ammonium bicarbonate overnight at $37^{\circ} \mathrm{C}$. Upon completion and digestion, $0.1 \%$ TFA was added per well. Each tryptic peptide mixture thus generated was concentrated, desalted with $\mathrm{C}_{18}$ ZipTip (Millipore, Billerica, MA, USA), and subsequently eluted with $4 \mathrm{mg}$ of cyano-4-hydroxycinnamic acid in $60 \%$ acetonitrile and $0.1 \%$ trifluoroacetic acid onto MALDI sample plate. The samples were analyzed on the 4800 Plus MALDI TOF/TOF analyzer (Applied Biosystems Inc., Foster City, CA, USA) equipped with Nd:YAG laser operating at $200 \mathrm{~Hz}$. All mass spectra were recorded from 750 to $4000 \mathrm{Da}$ in positive reflectron mode. MS spectra were recorded for all sample spots on the plate and internally calibrated using signals from auto-proteolytic fragments of trypsin. Up to three spectral peaks per spot that met threshold criterion were included in the acquisition list for the MS/MS spectra analysis. Peptide fragmentation was performed at collision energy of $1 \mathrm{kV}$ and collision gas pressure of $\sim 2 \times 10^{-7}$ Torr. MS and MS/MS spectra generated were searched against the Swiss-Prot and NCBI databases, respectively, using the Mascot software (Matrix Science, Boston, MA, USA). Monoisotopic peptide masses were used for combined MS and MS/MS database search in order to obtain protein identities. Following search criteria were applied: maximum allowed peptide mass error $20 \mathrm{ppm}$; fragment mass tolerance, $\pm 0.3 \mathrm{Da}$; minimum $5 \mathrm{~S} / \mathrm{N}$; and a maximum of one incomplete cleavage per peptide. Only significant hits defined by the Mascot scoring and probability analysis $(P=0.05)$ were accepted as significant results.

\section{qRT-PCR}

We tested expression of PAI-1 and TIMP-1 genes using SYBR Green-based qPCR. Total RNA was isolated from ND cells according previously described experiment for $\mathrm{RT}^{2}$ Profiler PCR Array and was reversely transcribed into cDNA by High Capacity cDNA Reverse Transcription Kit (Applied Biosystems) on GenAmp PCR System 2400 (Applied Biosystems). Primer pairs were designed by the software "Real Time PCR Tool" from Integrated DNA Technologies (http://eu.idtdna.com/scitools/ Applications/RealTimePCR/). Designed primers were tested for specificity to give only one band (confirmed by gel electrophoresis and melting curve analysis) and conditions of reactions were optimized so that efficiency of PCR reaction was 95-100\% (Table 1). Relative quantification values were obtained from the threshold cycle number of analyzed genes measured in triplicate and normalized with one most stable control gene using geNorm program. As control gene s18 rRNA was employed. Results were processed with REST 2008 V2.0.7.

After initial denaturation at $95^{\circ} \mathrm{C}$ for $3 \mathrm{~min}, 40$ cycles of PCR were performed in AB 7300 Real-Time PCR System (Applied Biosystems, Foster City, CA, USA). Each cycle included denaturation at $95^{\circ} \mathrm{C}$ for $1 \mathrm{~min}$, annealing at $60^{\circ} \mathrm{C}$ (see Table 1) for $30 \mathrm{~s}$, and extension at $72^{\circ} \mathrm{C}$ for $10 \mathrm{~s}$, followed by melting curve program.

\section{Collagen Gel Contraction Assay}

Collagen gels were prepared as described by Ngo et al. (2006). Briefly, fibroblasts were re-suspended in $400 \mu \mathrm{l}$ DMEM supplemented with $0.2 \%$ FCS and added to $200 \mu$ l collagen

TABLE 1 | Primers used for the qRT-PCR analysis.

\begin{tabular}{lllll}
\hline Gene & & Sequence $\mathbf{5}^{\prime} \mathbf{-} \mathbf{3}^{\prime}$ & Size & Conditions \\
\hline 18SrRNA & For & GTAACCCGTTGAACCCCATT & $151 \mathrm{bp}$ & $\begin{array}{l}60^{\circ} \mathrm{C}, 3.5 \mathrm{mM} \\
\mathrm{MgCl}_{2}\end{array}$ \\
& Rev & CCATCCAATCGGTAGTAGCG & & \\
\hline PAl-1 & For & TGGAACAAGGATGAGATCAG & $262 \mathrm{bp}$ & $60^{\circ} \mathrm{C}, 3 \mathrm{mM}$ \\
& Rev & CCGTTGAAGTAGAGGGCATT & & $\mathrm{MgCl}_{2}$ \\
\hline TIMP-1 & For & AGGCTCTGAAAAGGGCTTCCA & $150 \mathrm{bp}$ & $\begin{array}{l}60^{\circ} \mathrm{C}, 3 \mathrm{mM} \\
\mathrm{MgCl}_{2}\end{array}$ \\
& Rev & GAGTGGGAACAGGGTGGACA & &
\end{tabular}


suspension $(3 \mathrm{mg} / \mathrm{ml})$ yielding the final concentration of 150000 cells $/ \mathrm{ml}$ and $1 \mathrm{mg} / \mathrm{ml}$ collagen. Cell suspension containing $500 \mu \mathrm{l}$ collagen was cast into each well of 24-well tissue culture plate and incubated at $37^{\circ} \mathrm{C}$ for $1 \mathrm{~h}$ in order to facilitate polymerization. After gelation, the gels were released from the surface of the culture well using a sterile tip. Gels were pre-incubated with synthetic p38 phosphorylation inhibitor SB203580 for $1 \mathrm{~h}$. After stimulation with TGF- $\beta 1(3 \mathrm{ng} / \mathrm{mL})$ for 24,48 , and $72 \mathrm{~h}$ in the presence or absence of SB203580, contraction was digitally photo-documented at 24,48 , and $72 \mathrm{~h}$. Contraction quantification was performed using NIH image software (http:// rsb.info.nih.gov/nih-image/).

\section{RESULTS}

\section{Inflammatory and Autoimmune Gene Expression in Differentiating Primary DD Cells is Linked with the Activation of p38 MAPK Signaling}

We previously reported on the involvement of p38 MAPK signaling pathway in primary cells grown from DD patients (Ratkaj et al., 2012). In the present paper, we studied p38 MAPK downstream target, specifically MK2 kinase, during differentiation of primary ND cells into myofibroblasts. This kinase is exclusively phosphorylated by activated p38 and was previously implicated in myofibroblast differentiation and fibrotic processes other than DD (Liu et al., 2007). We detected stable endogenous expression of phosphorylated MK2 form in cells grown from macroscopically unaffected palmar fascia adjacent to diseased tissue (ND cells) prior and upon treatment with TGF- $\beta 1$ (Figure 1A). However, in cells coincubated with TGF- $\beta 1$ and $\mathrm{p} 38$ phosphorylation inhibitor, the levels of phosphorylated MK2 diminished. Interestingly, active form of MK2 was detected in untreated ND fibroblasts as well, which could be attributed to the well-known role of p38 MAPK signaling in homeostasis of palmar fascia fibroblasts or in the intrinsic predisposition of normal palmar fibroblasts in DD patients for disease development. Since MK2 is involved in the regulation of inflammatory response within $\mathrm{p} 38$-MAPK signaling pathway (Gaestel, 2013), we analyzed changes in the expression profile of genes involved in inflammation and autoimmune response during the differentiation process. Obtained results showed that activation of p38 MAPK signaling by TGF- $\beta 1$ in ND cells directly influences expression of a number of tested genes (Figure 1B) including genes encoding for chemokine (C$\mathrm{C}$ motif) ligand 11 (CCL11), interleukin 6 (IL-6), chemokine (C-C motif) ligand 2 (CCL2), and interleukin 1 receptor accessory protein (IL1RAP) that were found to be over-expressed. Inhibition of $\mathrm{p} 38$ phosphorylation partially reversed this process and significantly down-regulated genes CCL11 and IL1RAP. Similar down-regulation was also observed for $I L-6$. A number

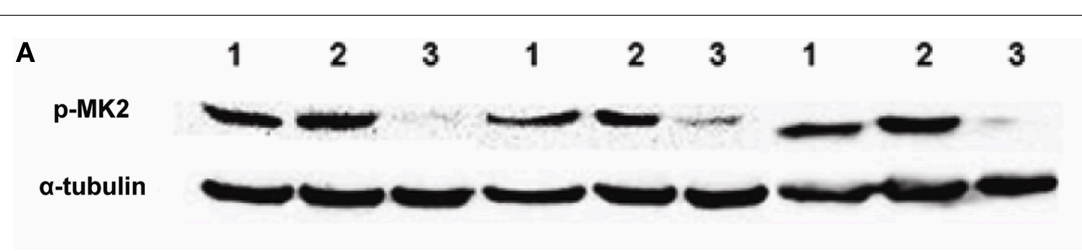

B

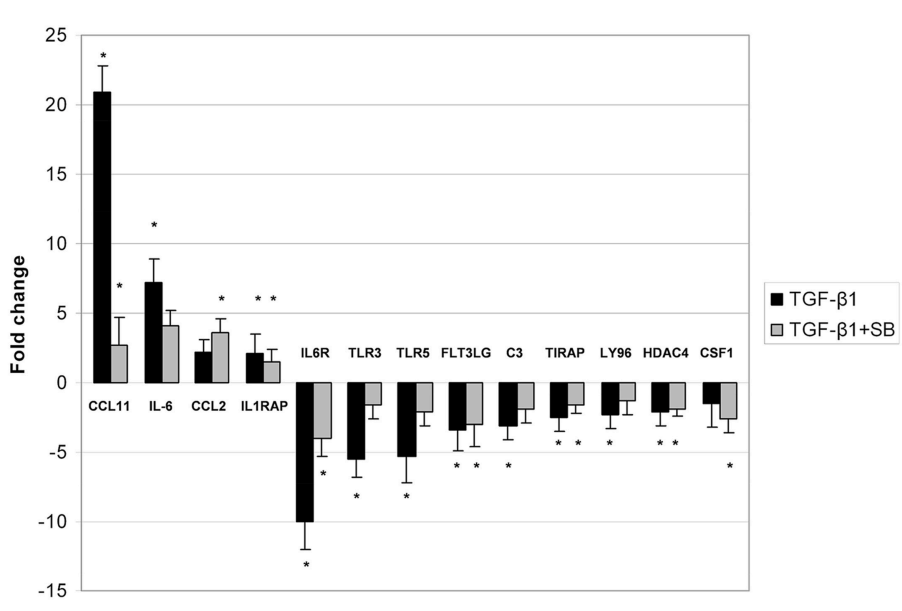

FIGURE 1 | Phosphorylation status of MAPKAPK-2 kinase and expression of cytokine and cytokine receptors in ND cells treated with TGF- $\beta 1$ or TGF- $\beta 1$ and inhibitor of p38 phosphorylation. Panel (A) representative western blots showing phosphorylated MAPKAPK-2 in untreated ND cells (1), ND cells treated with TGF- $\beta 1$ (2) and ND cells incubated with TGF- $\beta 1$ and p38 phosphorylation inhibitor SB203580 (3), expression of $\alpha$-tubulin in ND cells was used as loading control; Panel (B) changes in gene expression observed in ND fibroblasts treated with TGF- $\beta 1$ (black columns) or treated with TGF- $\beta 1$ and p38 phosphorylation inhibitor SB203580 (gray columns). The results are presented as gene expression fold change between treated cells and control. *Statistically relevant changes $(p<0.05)$ in comparison to control. 
of genes had lower expression levels in ND cells activated by TGF- $\beta 1$ including those coding for complement component (C3), fms-related tyrosine kinase 3 ligand (FLT3LG), interleukin 6 receptor (IL6R), lymphocyte antigen 96 (LY96), toll-interleukin 1 receptor $(T I R)$ domain containing adaptor protein $(T I R A P)$, toll-like receptor (TLR3), toll like receptor 5 (TLR5), and histone deacetylase 4 (HDAC4). Majority of the genes whose expression levels were altered by TGF- $\beta 1$ showed reversed expression pattern upon treatment with the inhibitor of p38 phosphorylation. Obtained results thus support previous studies reporting on p38 MAPK pathway involvement in inflammation processes during fibroblast differentiation. Since myofibroblastlike phenotype includes initiation of extensive extracellular matrix deposition driven by inflammatory factors such as for example TGF- $\beta 1$ and TNF- $\alpha$ (Reeves and Friedman, 2002), we profiled secretome of ND cells.

\section{Analysis of Proteins Secreted by ND Cells}

We analyzed all secreted proteins (the secretome) from untreated (control), TGF- $\beta 1$-activated ND cells and ND cells treated with TGF- $\beta 1$ and inhibitor of p38 phosphorylation (Figure 2). Differentially expressed proteins are presented in Table 2. Extracellular matrix proteins were expectedly identified as a major group of secreted proteins. Incubation with TGF$\beta 1$ alone or in combination with the p38 phosphorylation inhibitor induced expression of matrix metalloproteinase-2 (MMP-2), collagen alpha-5(VI) chain (COL4A5), plasminogen activator inhibitor 1 (PAI-1), and tissue inhibitor of matrix metalloproteinases 1 (TIMP-1), in comparison with control cells (Table 2). TIMPs and indirectly PAI-1 are key inhibitors of MMPs and other enzymes that degrade ECM proteins. Their expression was validated at the gene level as well (Figure 3). Addition of p38 phosphorylation inhibitor significantly decreased changes induced by TGF- $\beta 1$ treatment (diminished expression of TIMPs and PAI-1genes). Ulrich et al. (2009) showed that TIMP-1 is the only TIMP whose expression is increased significantly in the DD nodule in comparison with normal palmar fascia. Surprisingly, until now there was no evidence on PAI-1 gene expression in fibroblasts activated by TGF- $\beta 1$ from palmar fascia.

\section{Collagen Gel Contraction Assay}

Our previous results (Pavelic et al., 2009; Ratkaj et al., 2012) showed a connection between p38 MAPK activation and differentiation of fibroblasts into myofibroblasts and acquirement of their contractive phenotype. In the absence of an animal model to study the effect of p38 phosphorylation inhibition in DD cells during differentiation process, we used three-dimensional collagen lattice where the cells were grown on the mouse collagen type I layer. Type I collagen is abundantly present in healthy palmar fascia and therefore suitable to study fibroblast contraction during differentiation into myofibroblasts. Obtained results are presented in Figures 4A,B.

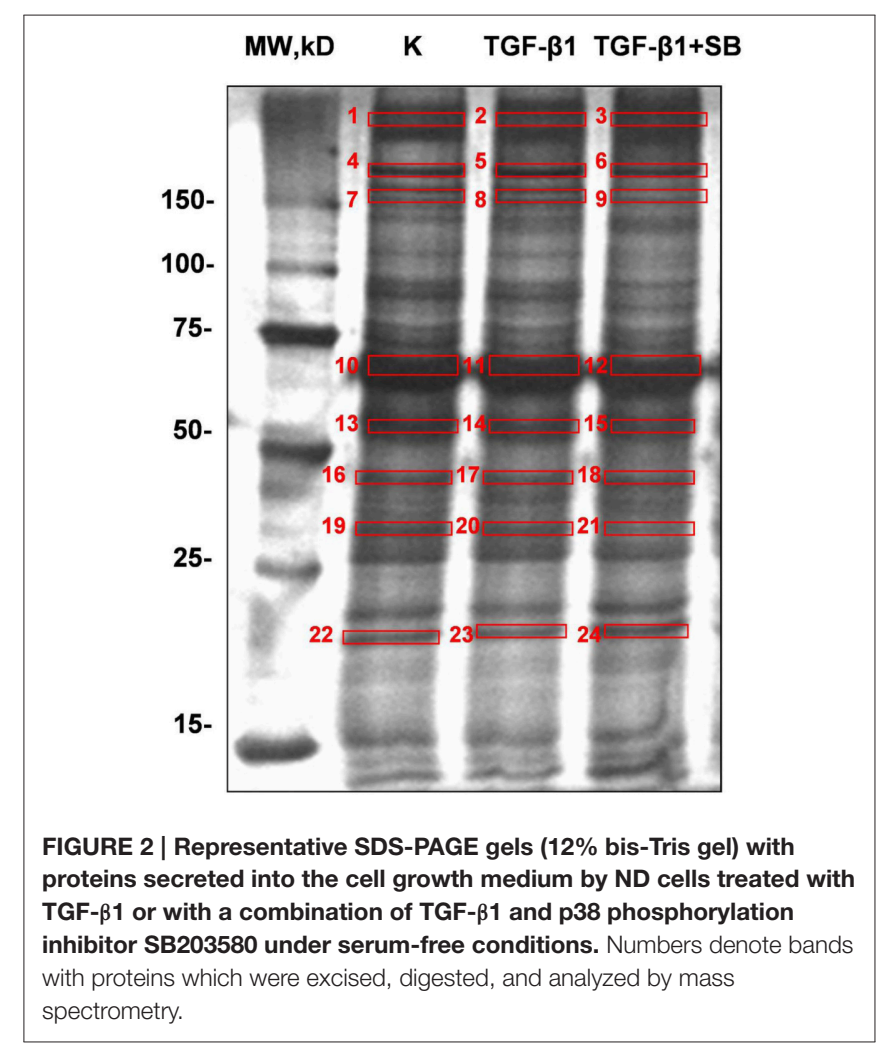

TABLE 2 | Proteins expressed in the cell growth medium of ND cells.

\begin{tabular}{|c|c|c|c|c|c|}
\hline $\begin{array}{l}\text { Position on } \\
\text { the gel }\end{array}$ & Protein name & Accession number/ncbi & MW & Treatment & Protein score $(\mathrm{Cl} \%)$ \\
\hline $1,2,3$ & Fibronectin 1/FN1 & gi|119590953 & 137,642 & Control, TGF $\beta$, TGF $\beta+$ SB & 100 \\
\hline 5 & Pro alpha 1(I) collagen COL1A2 & gi|186893270 & 138826.6 & TGF $\beta$ & 100 \\
\hline 8,9 & Collagen, type II, alpha 1/COL2A1 & gi|119578373 & 131077.4 & TGF $\beta$, TGF $\beta+$ SB & 100 \\
\hline 11,12 & Matrix metalloproteinase-2/MMP-2 & gi|5822007 & 70872.2 & $\mathrm{TGF} \beta, \mathrm{TGF} \beta+\mathrm{SB}$ & 100 \\
\hline 14,15 & Collagen alpha-5(VI) chain COL4A5 & gi|183583553 & 279755.7 & TGF $\beta$, TGF $\beta+$ SB & 100 \\
\hline 16,17 & Matrix metalloproteinase 1/MMP1 & gi|54697154 & 53947.7 & Control, TGF $\beta$ & 100 \\
\hline 20,21 & Plasminogen activator inhibitor -1/PAl-1 & gi|755747 & 143389.2 & TGF $\beta$, TGF $\beta+$ SB & 100 \\
\hline 23 & $\begin{array}{l}\text { Tissue inhibitor of matrix metalloproteinases } \\
1 / \text { TIMP-1 }\end{array}$ & gi|57210052 & 12526.5 & TGF $\beta$ & 100 \\
\hline
\end{tabular}

(1) Control ND cells (untreated cells), (2) ND cells treated with TGF- $\beta 1$ (3 ng/ml), and (3) ND cells treated with TGF- $\beta 1$ (3 ng/mL) and p38 phosphorylation inhibitor SB203580 (10 $\mu$ M). Proteins were resolved on SDS-PAGE, cut from the gel, digested, and identified by mass spectrometry. 

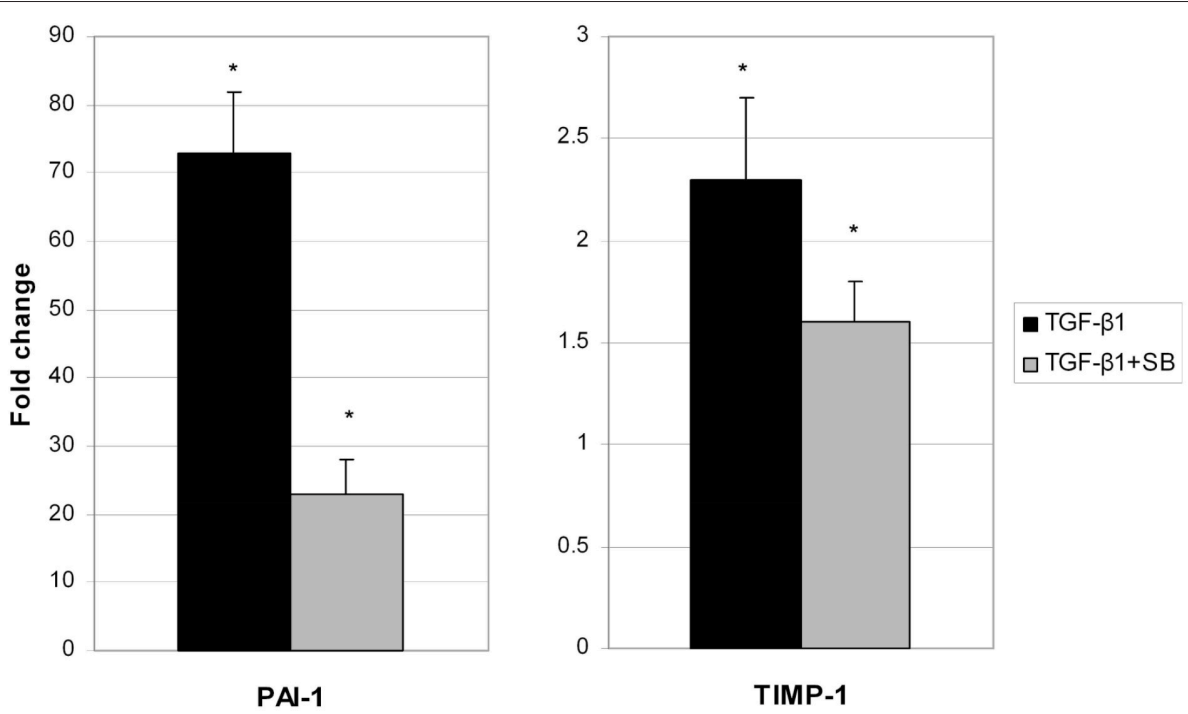

FIGURE 3 | Changes of PAI-1 and TIMP-1 gene expression in ND cells treated with TGF- $\beta 1$ (black columns) or with TGF- $\beta 1$ and p38 phosphorylation inhibitor SB203580 (gray columns). "Statistically relevant changes $(p<0.05)$ in comparison to control.
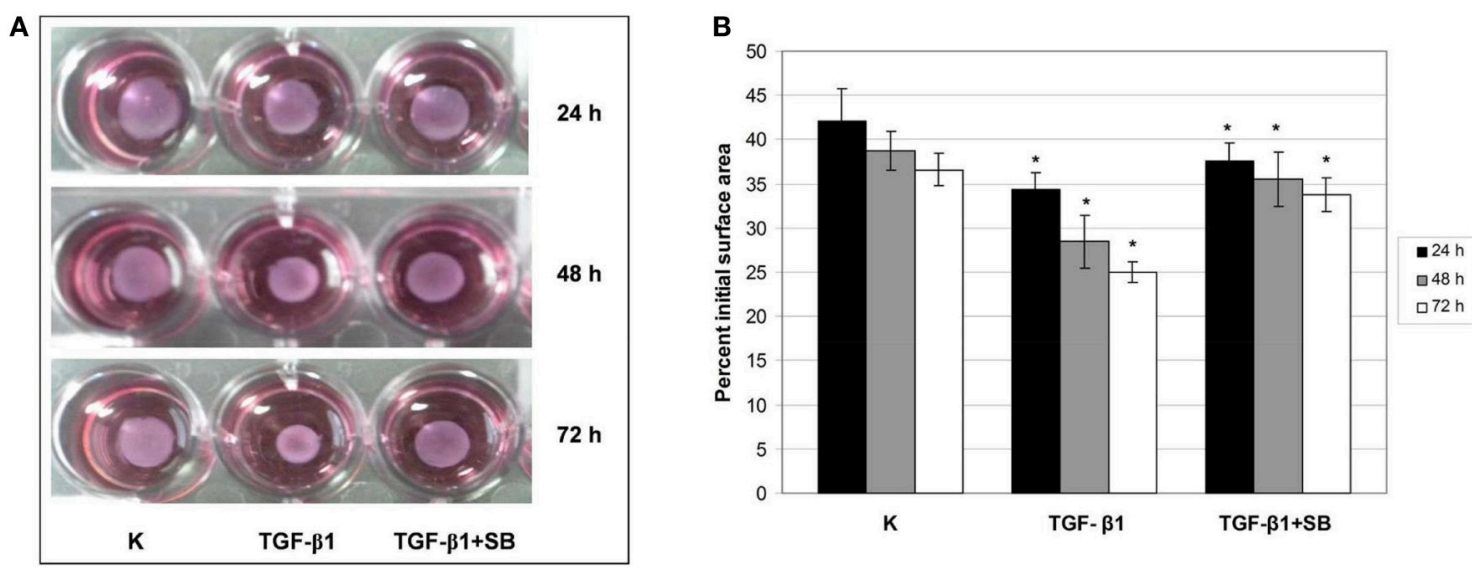

FIGURE 4 | TGF- $\beta 1-$ mediated contraction of ND fibroblast-populated collagen lattices is p38-dependent. ND cells were seeded in neutralized collagen solution and treated with TGF- $\beta 1$ or with a combination of TGF- $\beta 1$ and p38 phosphorylation inhibitor SB203580 for 24,48 , and $72 \mathrm{~h}$. Gels were detached, the gel contraction was digitally photo-documented (A) and measured as a reduction of gel surface 24 (black columns), 48 (gray columns), and $72 \mathrm{~h}$ (white columns) after detachment (B). *Statistically significant changes (ANOVA, $p>0.05$ ).

TGF- $\beta 1$ treatment significantly increased the contractility of cells after 24 -h treatment reducing the gel size to $34 \%$ of its initial size compared with reduction of $42 \%$ in the control group. After 48 -h incubation with TGF- $\beta 1$, gel size was reduced to $29 \%$ of the initial surface in comparison with control reduced to $39 \%$. Incubation of cells with TGF- $\beta 1$ for $72 \mathrm{~h}$ decreased the surface of the gel to $25 \%$ of the initial surface in contrast to the control with observed $37 \%$ initial area decrease. Addition of p38 phosphorylation inhibitor before TGF- $\beta 1$ stimulation blocked observed cell contraction. Thus, after 24-h treatment, gel surface was reduced to $38 \%$ of the initial surface area, after $48 \mathrm{~h}$ to $36 \%$ and after $72 \mathrm{~h}$ reduction was $34 \%$ of the initial surface. These results support the role of p38 activation in contractility of fibroblasts and their differentiation into myofibroblasts in the palmar region of DD patients.

\section{DISCUSSION}

Phenotypic changes during differentiation of fibroblasts into myofibroblasts are promoted by cytokines/chemokines and other immunomodulators (Lupher and Gallatin, 2006). This process is a persistent, yet localized inflammation that causes deposition of ECM components. Same processes are driven by TGF- $\beta 1$ in DD (Krause et al., 2011). TGF- $\beta 1$ protein family members transmit signals through type I and type II serine/threonine kinase receptors that further transduce the signal into the 
cytoplasm through phosphorylation of receptor-regulated Smad proteins. Activated R-Smads then regulate gene expression, i.e., expression of plasminogen activator inhibitor 1 gene (PAI-1), observed in the presented study as well (Table 2; (Krause et al., 2011)) and/or mitogen-activated protein (MAP) kinase signaling pathway genes (Figure 1; Moustakas and Heldin, 2005; Ratkaj et al., 2012). A number of papers describe the role of TGF$\beta 1$ in increased contractive properties of Dupuytren-derived cells (Wong and Mudera, 2006; Bisson et al., 2009). It has a role in induction of genes coding for ECM components as well, such as for example elastin, myelin basic protein and thrombospondin-1 (Ratkaj et al., 2012). In the presented study we analyzed cytokines and chemokines induced by TGF- $\beta 1$ in primary derived fibroblast from unaffected palmar tissue of DD patients. Upon treatment, the most prominently overexpressed inflammatory gene was chemokine 11 (CCL11). Expression levels of CCL11 diminished upon inhibition of p38 kinase phosphorylation (Figure 1B). Even though the role of chemokine CCL11 (eotaxin-1) was already described in proliferation of lung and bronchial fibroblasts (Rokudai et al., 2006), angiogenesis, expression of MMP-2, and the synthesis of type I collagen, its role was not described in cell contraction and differentiation processes (Huaux et al., 2005; Puxeddu et al., 2006). Therefore, CCL11 might be involved in the early phases of fibroblast differentiation when it induces upregulation of several fibrogenic factors or chemokines (Tomasek et al., 2002), where other factors, i.e., TGF- $\beta 1$ are required for further progression of this process. Furthermore, a role for CCL11 may be in triggering migration of progenitor mast cells toward the inflamed area and their activation during fibrotic changes (Price et al., 2003). Indeed, increased amount of mast cells was already observed in DD where they might actively participate in DD pathogenesis with CCL11 (Schubert et al., 2006). Additionally, it has been found that fibroblasts express CCR3 receptor that specifically binds the CCL11 ligand. Activated CCR3 probably induces fibroblasts proliferation and differentiation during fibrosis in an autocrine manner (Huaux et al., 2005). However, we were unable to detect CCR3 gene transcripts, meaning that it is either not expressed in palmar fibroblasts or its expression occurs later on during disease progression (Hogaboam et al., 1998; Huber et al., 2000). Altered gene expression level in ND cells treated with TGF- $\beta 1$ was observed for IL-6 gene as well. IL-6 is cytokine produced by fibroblasts where it contributes to the development of fibrosis and inhibition of fibroblasts' apoptosis (Bunker et al., 2000; Liu et al., 2007; Genotyping results for $I L-6$ gene are presented in Supplementary Material). IL-6 is a profibrogenic cytokine and its expression was already well-documented in different fibrotic diseases (Seong et al., 2009). Interestingly, primary fibroblasts grown from unaffected palmar fascia of DD patients express the $I L-6 R$ gene as well. Therefore, IL- 6 trans-signaling promotes release of IL- 6 from fibroblasts and endothelial cells in a positive autocrine feedback system, which is probably the case in our model as well.

Alteration in inflammatory genes observed in this study was accompanied by a number of proteins secreted in the cell growth media with a known role in ECM remodeling. These include matrix metalloproteinase 2 (MMP-2), tissue inhibitor of matrix metalloproteinase 1 (TIMP-1), and plasminogen activator inhibitor 1 (PAI-1) proteins. Overexpression of PAI-1 and TIMP-1 was validated on the gene level as well (Figure 3). Their transcripts levels diminished upon p38 phosphorylation inhibition. Similar results were reported by Leivonen et al. (2013) who identified p38 and ERK $1 / 2$ as the key signal transducers of TGF- $ß /$ Smad 3-induced overexpression of TIMP3. They also found an overexpression of TIMP1 and PAI-1 after treatment with TGF- $ß$, whose influence was attenuated with p38 inhibitor. Increased amounts of PAI-1 have also been described in other fibroproliferative diseases as well (Sisson and Simon, 2007; Wang et al., 2007). Moreover, Tuan et al. (2008) showed that treatment of keloid fibroblasts with PAI-1 specific polyclonal antibody or siRNA leads to decreased synthesis and deposition of the ECM. To our knowledge, the relationship between TGF- $\beta 1$ and PAI- 1 has not yet been described in DD tissues and we hypothesize that PAI-1 expression is probably increased in patients' palmar tissue as well. Furthermore, its role may include inhibition of metalloproteinases (MMP). The MMP expression is indeed usually low in homeostasis (Clark et al., 2008) but high during extracellular matrix deposition. For example, it was recently found that MMP-14 silencing inhibits activation of proMMP-2 in fibroblasts isolated from affected DD tissues and that silencing of MMP-14 and MMP-2 genes may inhibit cell-mediated contractions (Wilkinson et al., 2012). Similarly, we observed elevated levels of TIMP-1 in TGF- $\beta 1$ treated ND cells as well, which probably play a role in the inhibition of MMPs (Tuan et al., 2008). The balance between MMPs and TIMPs is critical for changes in the ECM and increased amounts of TIMPs have been previously observed in other fibrotic diseases (Chirco et al., 2006). For example, cords and nodules in DD have significantly increased levels of TIMP1, TIMP-2, and MMP-2 gene expression of in comparison with control samples (Ulrich et al., 2009). Our results are consistent with these data as TGF- $\beta 1$ increased the expression of TIMP1 and MMP-2 both at the gene and protein levels which was visible as increased contractile force in the gel-contraction assay. This process was again reversed by inhibition of p38 phosphorylation.

In conclusion, our study provides additional evidence on the p38 MAPK signaling events in primary cells derived from DD patients' palmar fascia. In particular, TGF- $\beta 1$-induced p38 phosphorylation in ND cells grown from macroscopically unaffected palmar fascia adjacent to the disease tissue of DD patients occurs with the activation of cytokine genes CCL-11 and $I L-6$ and secretion of extracellular matrix regulatory proteins PAI-1 and TIMP-1. Dual targeting of inflammation and p38 MAPK signaling in DD should be considered as a novel strategy for advancing the management of DD patients and prevention of disease recurrence.

\section{ETHICAL APPROVAL}

All procedures performed in studies involving human participants were in accordance with ethical standards of the institutional and/or national research committee and with 
the 1964 Helsinki declaration and its later amendments or comparable ethical standards.

\section{ACKNOWLEDGMENTS}

This work was supported by grants from the Croatian Ministry of Science, Education and Sports (grants no. 3350982464-2393 and 335-0000000-3532), University of Rijeka research grants (13.11.1.1.11 and 13.11.1.2.01.) and the National

\section{REFERENCES}

Baird, K. S., Alwan, W. H., Crossan, J. F., and Wojciak, B. (1993). T-cell-mediated response in dupuytren's disease. Lancet 341, 1622-1623. doi: 10.1016/01406736(93)90760-E

Bisson, M. A., Beckett, K. S., McGrouther, D. A., Grobbelaar, A. O., and Mudera, V. (2009). Transforming growth factor-betal stimulation enhances dupuytren's fibroblast contraction in response to uniaxial mechanical load within a 3-dimensional collagen gel. J. Hand Surg. 34, 1102-1110. doi: 10.1016/j.jhsa.2009.02.008

Brennan, D. C., Jevnikar, A. M., Takei, F., and Reubin-Kelley, V. E. (1990). Mesangial cell accessory functions: mediation by intercellular adhesion molecule-1. Kidney Int. 38, 1039-1046. doi: 10.1038/ki.1990.310

Bunker, T. D., Reilly, J., Baird, K. S., and Hamblen, D. L. (2000). Expression of growth factors, cytokines and matrix metalloproteinases in frozen shoulder. J. Bone Joint Surg. Br. 82, 768-773. doi: 10.1302/0301-620X.82B5.9888

Canbay, A., Taimr, P., Torok, N., Higuchi, H., Friedman, S., and Gores, G. J. (2003). Apoptotic body engulfment by a human stellate cell line is profibrogenic. Lab. Invest. 83, 655-663. doi: 10.1097/01.LAB.0000069036.63405.5C

Chirco, R., Liu, X. W., Jung, K. K., and Kim, H. R. (2006). Novel functions of TIMPs in cell signaling. Cancer Metastasis Rev. 25, 99-113. doi: 10.1007/s10555-0067893-x

Clark, I. M., Swingler, T. E., Sampieri, C. L., and Edwards, D. R. (2008). The regulation of matrix metalloproteinases and their inhibitors. Int. J. Biochem. Cell Biol. 40, 1362-1378. doi: 10.1016/j.biocel.2007.12.006

Gaestel, M. (2013). What goes up must come down: molecular basis of mapkap kinase 2/3-dependent regulation of the inflammatory response and its inhibition. Biol. Chem. 394, 1301-1315. doi: 10.1515/hsz-201 3-0197

Ghosh, A. K., and Vaughan, D. E. (2012). Pai-1 in tissue fibrosis. J. Cell Physiol. 227, 493-507. doi: 10.1002/jcp. 22783

Hogaboam, C. M., Gallinat, C. S., Bone-Larson, C., Chensue, S. W., Lukacs, N. W., Strieter, R. M., et al. (1998). Collagen deposition in a non-fibrotic lung granuloma model after nitric oxide inhibition. Am. J. Pathol. 153, 1861-1872. doi: 10.1016/S0002-9440(10)65700-8

Huang, C. Y., and Ogawa, R. (2012). Fibroproliferative disorders and their mechanobiology. Connect Tissue Res. 53, 187-196. doi: 10.3109/03008207.2011.642035

Huaux, F., Gharaee-Kermani, M., Liu, T. J., Morel, V., McGarry, B., Ullenbruch, M., et al. (2005). Role of eotaxin-1 (ccl11) and cc chemokine receptor 3 (ccr3) in bleomycin-induced lung injury and fibrosis. Am. J. Pathol. 167, 1485-1496. doi: 10.1016/S0002-9440(10)61235-7

Huber, M. A., Kraut, N., Addicks, T., and Peter, R. U. (2000). Cell-type-dependent induction of eotaxin and $\mathrm{ccr} 3$ by ionizing radiation. Biochem. Biophys. Res. Commun. 269, 546-552. doi: 10.1006/bbrc.2000.2287

Kalluri, R., and Zeisberg, M. (2006). Fibroblasts in cancer. Nat. Rev. Cancer 6, 392-401. doi: 10.1038/nrc1877

Knittel, T., Dinter, C., Kobold, D., Neubauer, K., Mehde, M., Eichhorst, S., et al. (1999). Expression and regulation of cell adhesion molecules by hepatic stellate cells (hsc) of rat liver - involvement of hsc in recruitment of inflammatory cells during hepatic tissue repair. Am. J. Pathol. 154, 153-167. doi: 10.1016/S00029440(10)65262-5

Krause, C., Kloen, P., and Ten Dijke, P. (2011). Elevated transforming growth factor beta and mitogen-activated protein kinase pathways mediate fibrotic
Employment and Development Agency grant "Development of a drug intended for treating the Dupuytren's disease patients" (14V09809).

\section{SUPPLEMENTARY MATERIAL}

The Supplementary Material for this article can be found online at: http://journal.frontiersin.org/article/10.3389/fmolb. 2015.00068

traits of dupuytren's disease fibroblasts. Fibrogenesis Tissue Repair 4:14. doi: 10.1186/1755-1536-4-14

Lagares, D., and Kapoor, M. (2013). Targeting focal adhesion kinase in fibrotic diseases. BioDrugs 27, 15-23. doi: 10.1007/s40259-012-0003-4

Leivonen, S. K., Lazaridis, K., Decock, J., Chantry, A., Edwards, D. R., and Kahari, V. M. (2013). Tgf-beta-elicited induction of tissue inhibitor of metalloproteinases (timp)-3 expression in fibroblasts involves complex interplay between smad3, p38alpha, and erk1/2. PLoS ONE 8:e57474. doi: 10.1371/journal.pone.0057474

Liu, T., Warburton, R. R., Guevara, O. E., Hill, N. S., Fanburg, B. L., Gaestel, M., et al. (2007). Lack of mk2 inhibits myofibroblast formation and exacerbates pulmonary fibrosis. Am. J. Respir. Cell Mol. Biol. 37, 507-517. doi: 10.1165/rcmb.2007-0077OC

Lupher, M. L. Jr., and Gallatin, W. M. (2006). Regulation of fibrosis by the immune system. Adv. Immunol. 89, 245-288. doi: 10.1016/S0065-2776(05)89006-6

Marra, F., Valente, A. J., Pinzani, M., and Abboud, H. E. (1993). Cultured human liver fat-storing cells produce monocyte chemotactic protein-1. Regulation by proinflammatory cytokines. J. Clin. Investig. 92, 1674-1680.

Moustakas, A., and Heldin, C. H. (2005). Non-smad tgf-beta signals. J. Cell Sci. 118, 3573-3584. doi: 10.1242/jcs.02554

Ngo, P., Ramalingam, P., Phillips, J. A., and Furuta, G. T. (2006). Collagen gel contraction assay. Methods Mol. Biol. 341, 103-109. doi: 10.1385/1-59745-113$4: 103$

Parsonage, G., Filer, A. D., Haworth, O., Nash, G. B., Rainger, G. E., Salmon, M., et al. (2005). A stromal address code defined by fibroblasts. Trends Immunol. 26, 150-156. doi: 10.1016/j.it.2004.11.014

Pavelic, S. K., Sedic, M., Hock, K., Vucinic, S., Jurisic, D., Gehrig, P., et al. (2009). An integrated proteomics approach for studying the molecular pathogenesis of dupuytren's disease. J. Pathol. 217, 524-533. doi: 10.1002/path.2483

Price, K. S., Friend, D. S., Mellor, E. A., De Jesus, N., Watts, G. F., and Boyce, J. A. (2003). Cc chemokine receptor 3 mobilizes to the surface of human mast cells and potentiates immunoglobulin e-dependent generation of interleukin 13. Am. J. Respir. Cell Mol. Biol. 28, 420-427. doi: 10.1165/rcmb.2002-0155OC

Puxeddu, I., Bader, R., Piliponsky, A. M., Reich, R., Levi-Schaffer, F., and Berkman, N. (2006). The cc chemokine eotaxin/ccl11 has a selective profibrogenic effect on human lung fibroblasts. J. Allergy Clin. Immunol. 117, 103-110. doi: 10.1016/j.jaci.2005.08.057

Ratkaj, I., Bujak, M., Jurisic, D., Baus Loncar, M., Bendelja, K., Pavelic, K., et al. (2012). Microarray analysis of dupuytren's disease cells: the profibrogenic role of the tgf-beta inducible p38 mapk pathway. Cell. Physiol. Biochem. 30, 927-942. doi: $10.1159 / 000341470$

Reeves, H. L., and Friedman, S. L. (2002). Activation of hepatic stellate cells - a key issue in liver fibrosis. Front. Biosci. 7, D808-D826. doi: 10.2741/reeves

Rokudai, A., Terui, Y., Kuniyoshi, R., Mishima, Y., Mishima, Y., Aizu-Yokota, E., et al. (2006). Differential regulation of eotaxin-1/CCL11 and eotaxin-3/CCL26 production by the TNF alpha and IL-4 stimulated human lung fibroblast. Biol. Pharm. Bull. 29, 1102-1109. doi: 10.1248/bpb.29.1102

Samarakoon, R., Overstreet, J. M., and Higgins, P. J. (2013). Tgf-beta signaling in tissue fibrosis: redox controls, target genes and therapeutic opportunities. Cell. Signal. 25, 264-268. doi: 10.1016/j.cellsig.2012.10.003

Schubert, T. E. O., Weidler, C., Borisch, N., Schubert, C., Hofstadter, F., and Straub, R. H. (2006). Dupuytren's contracture is associated with sprouting of substance p positive nerve fibres and infiltration by mast cells. Ann. Rheum. Dis. 65, 414-415. doi: 10.1136/ard.2005.044016 
Schwabe, R. F., Schnabl, B., Kweon, Y. O., and Brenner, D. A. (2001). Cd40 activates nf-kappa b and c-jun n-terminal kinase and enhances chemokine secretion on activated human hepatic stellate cells. J. Immunol. 166, 6812-6819. doi: 10.4049/jimmunol.166.11.6812

Sempowski, G. D., Chess, P. R., and Phipps, R. P. (1997). Cd40 is a functional activation antigen and b7-independent $t$ cell costimulatory molecule on normal human lung fibroblasts. J. Immunol. 158, 4670-4677.

Seong, G. J., Hong, S., Jung, S. A., Lee, J. J., Lim, E., Kim, S. J., et al. (2009). Tgf-beta-induced interleukin-6 participates in transdifferentiation of human tenon's fibroblasts to myofibroblasts. Mol. Vis. 15, 2123-2128.

Shevchenko, A., Tomas, H., Havlis, J., Olsen, J. V., and Mann, M. (2006). In-gel digestion for mass spectrometric characterization of proteins and proteomes. Nat. Protoc. 1, 2856-2860. doi: 10.1038/nprot.2006.468

Sisson, T. H., and Simon, R. H. (2007). The plasminogen activation system in lung disease. Curr. Drug Targets 8, 1016-1029. doi: 10.2174/1389450077 81662319

Tomasek, J. J., Gabbiani, G., Hinz, B., Chaponnier, C., and Brown, R. A. (2002). Myofibroblasts and mechano-regulation of connective tissue remodelling. Nat. Rev. Mol. Cell Biol. 3, 349-363. doi: 10.1038/nrm809

Tse, R., Howard, J., Wu, Y., and Gan, B. S. (2004). Enhanced dupuytren's disease fibroblast populated collagen lattice contraction is independent of endogenous active tgf-beta(2). BMC Musculoskelet. Disord. 5:41. doi: 10.1186/14712474-5-41

Tuan, T. L., Hwu, P., Ho, W., Yiu, P., Chang, R., Wysocki, A., et al. (2008). Adenoviral overexpression and small interfering rna suppression demonstrate that plasminogen activator inhibitor-1 produces elevated collagen accumulation in normal and keloid fibroblasts. Am. J. Pathol. 173, 1311-1325. doi: 10.2353/ajpath.2008.080272

Ulrich, D., Ulrich, F., Piatkowski, A., and Pallua, N. (2009). Expression of matrix metalloproteinases and their inhibitors in cords and nodules of patients with dupuytren's disease. Arch. Orthop. Trauma. Surg. 129, 1453-1459. doi: 10.1007/s00402-008-0726-3
Verjee, L. S., Verhoekx, J. S. N., Chan, J. K. K., Krausgruber, T., Nicolaidou, V., Izadi, D., et al. (2013). Unraveling the signaling pathways promoting fibrosis in dupuytren's disease reveals tnf as a therapeutic target. Proc. Natl. Acad. Sci. U.S.A. 110, E928-E937. doi: 10.1073/pnas.1301100110

Wang, H., Zhang, Y., and Heuckeroth, R. O. (2007). Pai-1 deficiency reduces liver fibrosis after bile duct ligation in mice through activation of tpa. FEBS Lett. 581, 3098-3104. doi: 10.1016/j.febslet.2007.05.049

Wilkinson, J. M., Davidson, R. K., Swingler, T. E., Jones, E. R., Corps, A. N., Johnston, P., et al. (2012). Mmp-14 and mmp-2 are key metalloproteases in dupuytren's disease fibroblast-mediated contraction. Biochim. Biophys. Acta 1822, 897-905. doi: 10.1016/j.bbadis.2012.02.001

Wong, M., and Mudera, V. (2006). Feedback inhibition of high tgf-betal concentrations on myofibroblast induction and contraction by dupuytren's fibroblasts. J. Hand Surg. 31, 473-483. doi: 10.1016/j.jhsb.2006.05.007

Wynn, T. A. (2008). Cellular and molecular mechanisms of fibrosis. J. Pathol. 214, 199-210. doi: 10.1002/path.2277

Yellin, M. J., Winikoff, S., Fortune, S. M., Baum, D., Crow, M. K., Lederman, S., et al. (1995). Ligation of cd40 on fibroblasts induces cd54 (icam-1) and cd106 (vcam-1) up-regulation and il-6 production and proliferation. J. Leukoc. Biol. $58,209-216$.

Conflict of Interest Statement: The authors declare that the research was conducted in the absence of any commercial or financial relationships that could be construed as a potential conflict of interest.

Copyright (c) 2015 Bujak, Ratkaj, Markova-Car, Jurišić, Horvatić, Vučinić, Lerga, Baus-Lončar, Pavelić and Kraljević Pavelić. This is an open-access article distributed under the terms of the Creative Commons Attribution License (CC BY). The use, distribution or reproduction in other forums is permitted, provided the original author(s) or licensor are credited and that the original publication in this journal is cited, in accordance with accepted academic practice. No use, distribution or reproduction is permitted which does not comply with these terms. 